\title{
Digestive stability and acute toxicity studies of exogenous protein in transgenic rice expressing lysine-rich fusion proteins
}

\author{
ZHAO XiangXiang ${ }^{1}$, HU XiaoLan ${ }^{1}$, TANG Tang ${ }^{1}$, LU ChangLi $^{1}$, LIU FuXia $^{1}$, JI LiLian $^{1 *}$ \& \\ LIU QiaoQuan ${ }^{2 *}$

\begin{abstract}
${ }^{1}$ Jiangsu Key Laboratory for Eco-Agricultural Biotechnology around Hongze Lake, Huaiyin Normal University, Huaian 223300, China;
${ }^{2}$ Key Laboratory of Crop Genetics and Physiology of the Jiangsu Province and Plant Functional Genomics of the Ministry of Education,

Yangzhou University, Yangzhou 225009, China
\end{abstract}

Received February 3, 2013; accepted March 25, 2013

\begin{abstract}
Evaluating exogenous protein expressed in transgenic crops is one of the most effective methods of assessing the safety of transgenic plants. The objective of this study was to assess the food safety of genetically modified (GM) rice containing a lysine-rich fusion protein gene (transgenic GL gene rice) by in vitro digestion and acute toxicity testing of exogenous protein, according to the national standard of the People's Republic of China. The exogenous protein was rapidly degraded in the simulated gastric and intestinal fluids. In the acute experiment, the exogenous protein was injected into Institute of Cancer Research (ICR) mice via the tail vein at a dose of $438 \mathrm{mg} \mathrm{kg}^{-1}$ body weight. No adverse effects on animal behavior or mortality were observed during the following 15-day period and there were no significant biological changes in body weight, serum biochemistry parameters, relative organ weights or histopathological examinations, compared with the control group. Therefore, exogenous protein in transgenic GL gene rice has a low potential allergenicity or toxicity risk.
\end{abstract}

transgenic rice, lysine-rich, exogenous protein, digestive stability, acute toxicity

Citation: Zhao X X, Hu X L, Tang T, et al. Digestive stability and acute toxicity studies of exogenous protein in transgenic rice expressing lysine-rich fusion proteins. Chin Sci Bull, 2013, 58: 2460-2468, doi: 10.1007/s11434-013-5923-y

Rice (Oryza sativa L.) is a major food crop, providing a staple food for nearly half of the world's population [1]. In Asia, rice provides more than $80 \%$ of the nutritional energy and more than $68 \%$ of the protein intake [2]. However, the content of lysine in rice is very low and is acknowledged as the most limiting essential amino acid in rice protein [3]. Lysine deficiency significantly reduces the biological utilization of rice protein and affects the nutritional status of people in regions where rice is the staple food. Therefore, increasing the lysine content of rice is of utmost importance. An increase in lysine can balance its nutritional quality, improve the bioavailability of rice protein and benefit human health. In recent years, agronomists and plant breeders have used genetic engineering technology to successfully increase the lysine content in several agricultural species,

*Corresponding authors (email: j112663@sina.com; qqliu@yzu.edu.cn) such as rice, maize, canola (oilseed rape) and soybean [4-7].

Although transgenic crops have some desirable traits, such as increased crop yield, improved nutritional value, disease and insect resistance, herbicide resistance and salt tolerance, etc., the food safety of transgenic crops is still an issue of widespread public concern. The inserted gene or its expression product, are likely to disturb the metabolism of the recipient crop species to some extent and these changes may affect the nutritional value of the crop product. They may even produce some new allergenic or toxic substances [8-10]. Therefore, to ensure the safety of transgenic crops and products, a number of measures aimed at improving the food safety of transgenic crops have been established by many countries and international organizations [11-13].

Currently, the food safety assessment of transgenic crops is based on the concept of substantial equivalence, original- 
ly proposed by the international Organization of Economic Cooperation and Development (OECD) and further elaborated by the UN Food and Agriculture Organization (FAO)/ World Health Organization (WHO) [14,15]. However, the evaluation of substantial equivalence is only an analytical exercise that investigates composition during the safety assessment of a new transgenic crop, relative to its traditional non-transgenic counterpart, and is considered a starting point rather than an end point in risk assessment [16]. Potential toxicity and unexpected effects are important parts of the safety assessment of GM crops, especially regarding the toxic and allergenic properties of exogenous protein introduced into GM crops [17-23]. For example, Lu et al. [18] performed an in vitro digestibility test and an animal test of hygromycin B phosphotransferase (HPT) protein produced by the prokaryotic expression system. The results showed that HPT protein was completely digested within $40 \mathrm{~s}$ in the simulated gastric fluid and did not induce any hypersensitivity reactions on brown Norway $(\mathrm{BN})$ rats treated with HPT protein via gavage for 42 days. The absence of adverse reactions to phosphinothricin acetyltransferase (PAT) proteins and Cry $1 \mathrm{C}$ protein were also confirmed in a similar manner [17,22].

The experimental material in this study was a new strain of high-lysine transgenic rice, which was created using a fusion-protein approach that can be illustrated by modifying the rice native Gt1 gene encoding glutelin storage protein by fusing with a heterologous cDNA encoding a lysine-rich protein (LRP) from winged bean to form a Gt: LRP fusion protein gene (named as GL fusion protein gene). This fusion protein gene can be successfully transferred into its parent rice (Wuxiangjing 9), which is a high-yielding rice variety grown in China [24]. Winged bean and the parent rice have a long history of safe cultivation as food crops and LRP and glutelin are also innocuous. However, the possible allergenicity and toxicity of the exogenous protein still needed to be investigated. Therefore, it was necessary to explore the safety of the exogenous protein in transgenic GL gene rice.

The objective of this study was to assess the safety of exogenous protein in transgenic GL gene rice through in vitro digestion testing and acute toxicity testing of the exogenous protein, according to the national standard of the People's Republic of China [13,25]. This study will provide scientific evidence for the evaluation of the food safety of transgenic GL gene rice.

\section{Materials and methods}

\subsection{Test materials and test animals}

Transgenic GL gene rice and the corresponding non-GM parental rice (Wuxiangjing 9) were provided by the Key Laboratory of Plant Functional Genomics of the Ministry of Education, Yangzhou University.
A total of 20 male and 20 female Institute of Cancer Research (ICR) mice, approximately 6-8 weeks old (with weight of $20 \pm 2 \mathrm{~g}$ ), were obtained and housed in the experimental animal center laboratory at Jiangsu University (Zhenjiang, China, license No. SCXK (SU) 2009-0002). Five animals of the same gender and treatment were housed together per cage in stainless steel wire cages in the animal room. The room temperature and relative humidity were maintained at $22 \pm 2^{\circ} \mathrm{C}$ and $50 \pm 5 \%$, respectively.

\subsection{Preparation of exogenous protein}

The total protein of rice seed was extracted using the method reported by Yamagata et al. [26] and was identified by SDS-PAGE and Western blotting [27]. Exogenous protein was obtained by cutting protein bands $(\sim 75 \mathrm{kD})$ [24] using a Micro Protein PAGE Recovery Kit (Sangon Biotech Co., Ltd, Shanghai) according to the manufacturer's instructions. These proteins were further verified by SDS-PAGE and Western blotting. The SDS-PAGE procedure used SM0661 (Fermentas) as molecular-weight protein markers. For Western blotting, the primary antibody was rabbit polyclonal antibodies raised against LRP provided by the Key Laboratory of Plant Functional Genomics of the Ministry of Education (Yangzhou University). The secondary antibody was a horseradish peroxidase (HRP) conjugated goat anti-rabbit IgG (HuaAn Biotech Co., Ltd, Hangzhou).

The concentration of total protein in the transgenic rice was measured using a BioPhotometer 6131 (Eppendorf, Hamburg, Germany) and the ratio of exogenous protein to total protein was analyzed with Quantity One software (Bio$\mathrm{Rad})$. After measuring the concentration of exogenous protein using the same method, the recovery rate was calculated as follows: recovery rate $=($ recovered exogenous protein content $) /($ exogenous protein content in total protein).

\section{3 vitro digestive stability tests}

(i) Simulated gastric fluid (SGF) assay. The SGF assay was performed according to the Ministry of Agriculture of PR China No. 869 Bulletin 2-2007 [25]. The concentration of exogenous protein in SGF was $5 \mathrm{~g} \mathrm{~L}^{-1}$. Exogenous protein was digested in a solution of pepsin (3772 $\mathrm{U} \mathrm{mg}^{-1}$ pro) with reaction times of $0 \mathrm{~s}, 15 \mathrm{~s}, 2 \mathrm{~min}, 10 \mathrm{~min}, 20 \mathrm{~min}, 30$ $\mathrm{min}$ and $60 \mathrm{~min}$. The stability of the exogenous protein in SGF was investigated by SDS-PAGE and Western blotting. Two reference proteins: soybean trypsin inhibitor (STI) and $\alpha$-casein $(\alpha-C S)$, were used as stable and labile controls, respectively. The digestion reaction was repeated twice, with three electrophoreses each time. Both a pepsin control and a sample protein control without pepsin were used in the experiments.

All of the reagents, except the reagents used for SDSPAGE and Western blotting, were purchased from Sigma-Aldrich Corporation (St. Louis, MO, USA). 
(ii) Simulated intestinal fluid (SIF) assay. The SIF assay was performed according to the Ministry of Agriculture of PR China No. 869 Bulletin 2-2007 [25]. Exogenous protein was tested for stability in SIF with pancreatin using digestion times of $0 \mathrm{~s}, 15 \mathrm{~s}, 2 \mathrm{~min}, 10 \mathrm{~min}, 20 \mathrm{~min}, 30 \mathrm{~min}$ and $60 \mathrm{~min}$. Then the samples were analyzed by SDSPAGE and Western blotting. The protocol was based on the above procedure except that SIF was used instead of SGF. In addition, the concentration of exogenous protein in SIF was $2 \mathrm{~g} \mathrm{~L}^{-1}$. Two reference proteins: soybean trypsin inhibitor (STI) and bovine $\beta$-lactoglobulin (BLG), were used as stable and labile controls, respectively. The digestion reactions were repeated twice, with three electrophoreses each time. A pancreatin control and a sample protein control without panreatin were used in the experiments.

All reagents, except the reagents used for SDS-PAGE and Western blotting, were purchased from Sigma-Aldrich Corporation. (St. Louis, MO, USA).

\subsection{Acute toxicity testing of exogenous protein in ICR mice}

(i) Experimental design. In order to evaluate whether exogenous protein produces an acute toxic effect on mammals, an acute toxicity study in ICR mice was conducted using the intravenous injection of exogenous protein method previously reported in the scientific literature $[17,28]$. The ICR mice were divided into four groups according to their sex and weight as follows: there was a group treated with an exogenous protein injection, a negative control group treated with a bovine serum albumin (BSA) injection, a positive control group treated with a melittin injection and a blank control group treated with a physiological saline injection. There were 10 mice in each group. Half were male and half female.

The rationale behind the injection dose of exogenous protein selected in this experiment was as follows: the daily intake of cereal for a normal adult male (approximate weight $70 \mathrm{~kg}$ ) recommended by Chinese Nutrition Society is $500 \mathrm{~g}$ [29]. Assuming that this cereal is all rice, the maximum daily intake of total protein for an adult was calculated using the total protein content of transgenic GL rice $(\sim 9.2 \%)$ [24]. Thus, the maximum daily intake of exogenous protein from transgenic GL rice for an adult was calculated according to the exogenous protein content of total protein. The weight coefficient was then calculated [30] and converted into the maximum daily intake of the exogenous protein per kilo equivalent of mice. Finally, the mouse tail vein injection dose of exogenous protein $\left(438 \mathrm{mg} \mathrm{kg}^{-1}\right)$ was calculated according to the conversion relationship between the lavage quantity and the intravenous injection quantity for a mouse [30]. The injection doses in the negative control group and the blank control group were the same as the exogenous protein group. The positive control group was injected with a melittin lethal dose of $3.1 \mathrm{mg} \mathrm{kg}^{-1}$ [31]. The mouse tail vein injection dose in all four experiments was $10 \mathrm{~mL} \mathrm{~kg}^{-1}$ weight.

The mice were fed for 3-5 d before injection in order to adapt the mice to the environment used in the screening system. They were fed with normal feed, had free access to food and drinking water and were observed continuously for $15 \mathrm{~d}$.

(ii) Clinical observation and body weights. All the mice were observed for signs of mortality or morbidity (the overt signs of toxicity), abnormal behavior and changes in appearance at least once a day throughout the study. They were weighed on the day of the first treatment (Day 0) and every $5 \mathrm{~d}$ thereafter. Individual body weight changes were calculated.

(iii) Serum chemistry assay. Whole blood was collected from the eyes of euthanized mice $15 \mathrm{~d}$ after injection. Following centrifugation, the sera were assayed for alanine aminotransferase (ALT), aspartate aminotransferase (AST), alkaline phosphatase (ALP), albumin (ALb), globulin (GLb), triglycerides (TG), cholesterol (CHOL), blood urea nitrogen (BUN) and glucose (GLU) levels using an Olympus AU2700 Clinical Chemistry Analyzer (Olympus, Tokyo, Japan).

(iv) Organ weight and histopathology. All the surviving mice were weighed before they were anesthetized with $10 \%$ chloral hydrate and sacrificed by exsanguination. A thorough necropsy was performed and the following organs were sequentially excised: the brain, heart, liver, spleen, lungs, kidneys, stomach, duodenum, thymus, ovaries and testes of each individual. Each organ was immediately weighed and the relative organ weight was calculated as a percentage of the total body weight. Tissue from each organ was fixed in $10 \%$ neutral buffered formalin, embedded in paraffin and then 5-6 $\mu \mathrm{m}$ thick sections were made and stained with standard hematoxylin-eosin for examination under a light microscope.

(v) Statistical analysis. The experimental data were expressed as means with standard deviations $(\bar{X} \pm S D)$, and analyzed using SPSS16.0 software at a significance level of $P<0.05$. Data from the males and females were analyzed separately.

\section{Results}

\subsection{Identification of exogenous protein}

An exogenous protein band of around $75 \mathrm{kD}$ [24] was detected only in the transgenic GL gene rice and was confirmed by SDS-PAGE (Figure 1(a)) and Western blotting analysis (Figure 1(b)).

Exactly $45.4 \mathrm{mg}$ total protein was extracted from $670 \mathrm{mg}$ GM rice flour. The results of the Quantity One software analysis showed that the exogenous protein accounted for approximately $20 \%$ of the total protein. The weight of exogenous protein recovered from the gel was $6.374 \mathrm{mg}$, with 
(a)

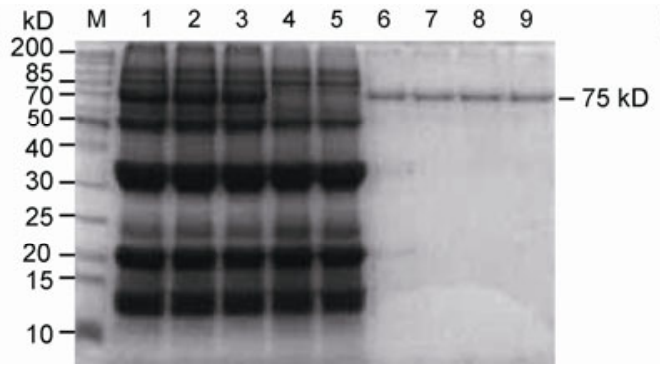

(b)

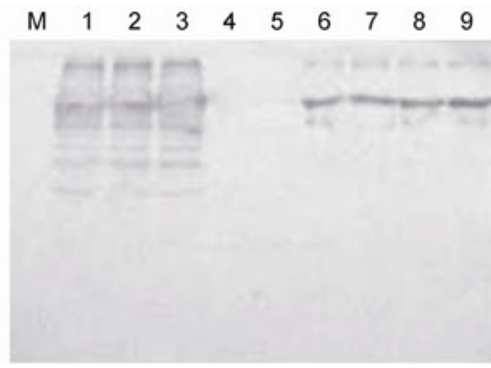

Figure 1 Identification of exogenous protein by SDS-PAGE (a) and Western blotting (b). M, Marker protein SM0661; lanes 1-3, total protein in the transgenic rice; lanes 4 and 5, total protein in the non-transgenic control rice; and lanes 6-9, exogenous protein recovered from the gel.

a recovery rate of $70.20 \%$. Using this method, sufficient exogenous protein was obtained for further digestive stability testing and acute toxicity testing.

\subsection{In vitro digestibility of exogenous protein}

(i) Digestibility of exogenous protein in SGF. As shown in Figure 2, the stable control STI could not be completely digested after $60 \mathrm{~min}$ in SIF, while the labile control $\alpha$ casein was completely digested after $15 \mathrm{~s}$ in SGF, which indicated that the pepsin was highly active in the SGF assay.

The results for the exogenous protein digested in SGF showed that, at the initiation of incubation (time zero), digestion of exogenous protein had not begun. After $15 \mathrm{~s}$, the exogenous protein had been completely digested and fragments of approximately $25 \mathrm{kD}$ and $15 \mathrm{kD}$ appeared. These fragments were not fully digested after 2 min and were not completely digested until the digestion time reached $10 \mathrm{~min}$ (Figure 3).

According to the China national standard (Ministry of Agriculture Bulletin No. 869-2-2007) [25], exogenous protein in transgenic GL gene rice is digestible in SGF.

(ii) Digestibility of exogenous protein in SIF. The stable control, STI, was persistently resistant to hydrolysis at $t>60 \mathrm{~min}$, while the labile control, BLG, underwent rapid hydrolysis $(t<15 \mathrm{~s})$ (Figure 4$)$. This result confirmed that pancreatin was highly active in the SIF assay.

The results for exogenous protein digested in SIF showed that exogenous protein was very rapidly and completely degraded within $15 \mathrm{~s}$ (Figure 5). According to the China national standard (Ministry of Agriculture Bulletin No. 869-2-2007) [25], exogenous protein in transgenic GL gene rice is extremely digestible in SIF. (a)

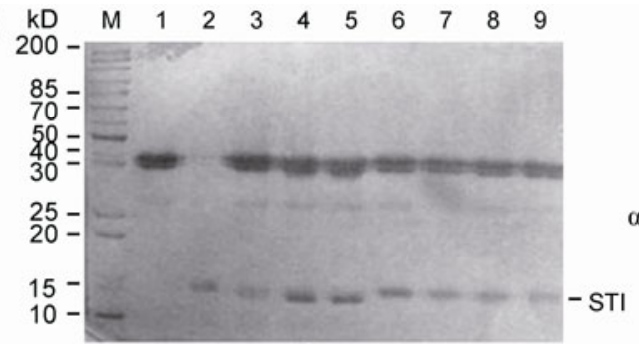

(b) $\begin{array}{lllllllllll}\mathrm{M} & 1 & 2 & 3 & 4 & 5 & 6 & 7 & 8 & 9\end{array}$

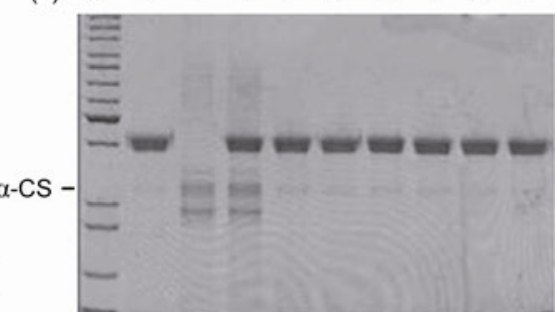

Figure 2 Simulated gastric digestion results for the stable and labile controls by SDS-PAGE analysis. M, Marker protein SM0661; lane 1, pepsin; lane 2, the stable control STI (a) and the labile control $\alpha$-casein (b); and lanes 3-9, control protein digested for $0 \mathrm{~s}, 15 \mathrm{~s}, 2 \mathrm{~min}, 10 \mathrm{~min}, 20 \mathrm{~min}, 30 \mathrm{~min}$ and $60 \mathrm{~min}$, respectively.

(a)

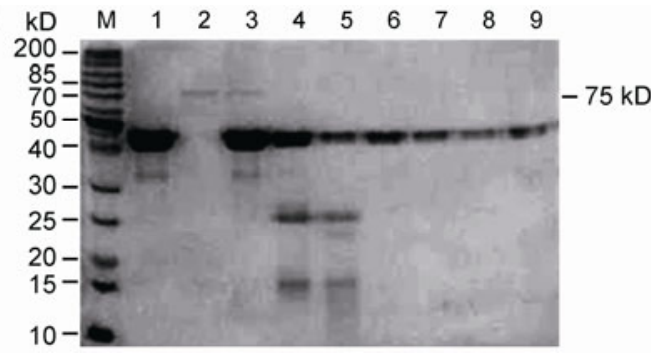

(b)

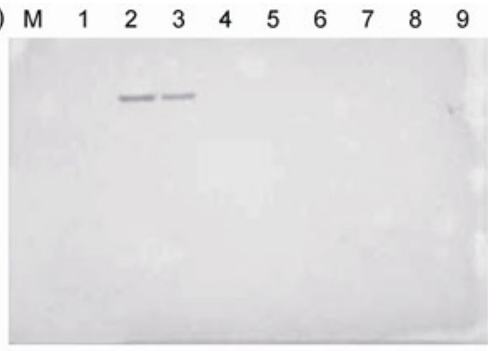

Figure 3 SDS-PAGE (a) and Western blotting (b) of exogenous protein digested in SGF. M, Marker protein SM0661; lane 1, pepsin; lane 2, exogenous protein in SGF without pepsin and incubation; and lanes 3-9, exogenous protein digested for $0 \mathrm{~s}, 15 \mathrm{~s}, 2 \mathrm{~min}, 10 \mathrm{~min}, 20 \mathrm{~min}, 30 \mathrm{~min}$ and $60 \mathrm{~min}$, respectively. 
(a)

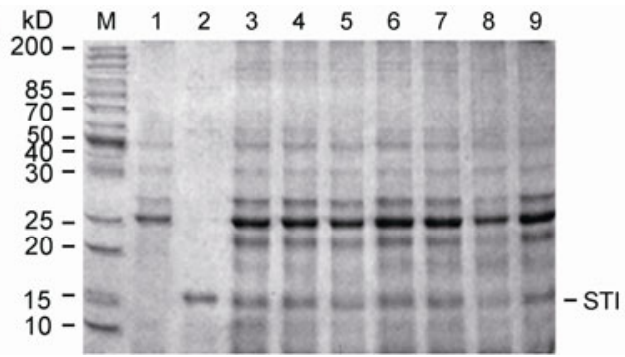

(b)

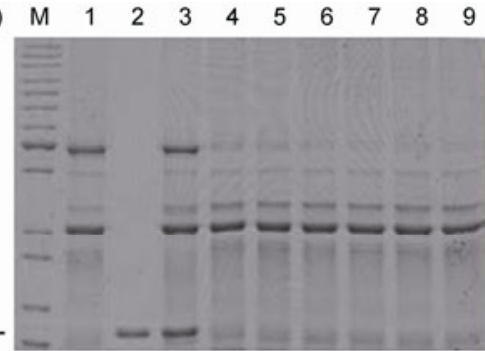

Figure 4 Simulated intestinal digestion results for the stable and labile controls by SDS-PAGE analysis. M, Marker protein SM0661; lane 1, pancreatin; lane 2, the stable control, STI (a) and the labile control, BLG (b); and lanes 3-9, control protein digested for 0 s, 15 s, 2 min, 10 min, 20 min, 30 min and 60 min, respectively.

(a)

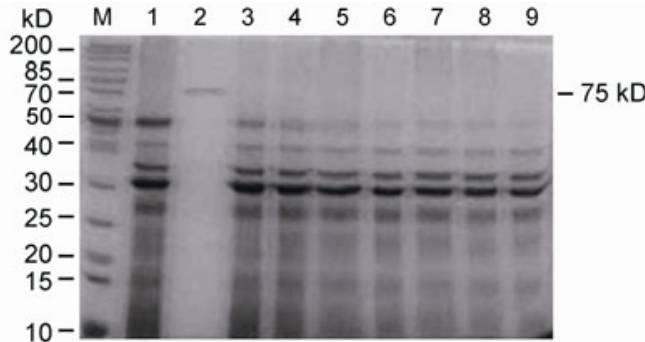

(b) $\begin{array}{llllllllll}M & 1 & 2 & 3 & 4 & 5 & 6 & 7 & 8 & 9\end{array}$

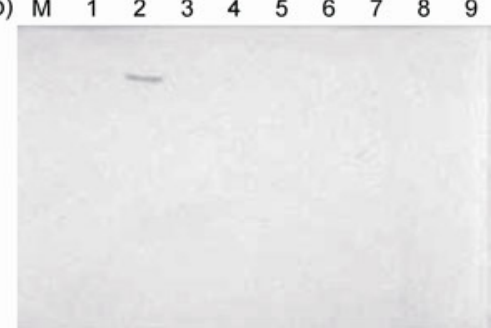

Figure 5 SDS-PAGE (a) and Western blotting (b) of exogenous protein digested in SIF. M, Marker protein SM0661; lane 1, pancreatin; lane 2, exogenous protein in SIF without pancreatin and incubation; and lanes 3-9, exogenous protein digested for $0 \mathrm{~s}, 15 \mathrm{~s}, 2 \mathrm{~min}, 10 \mathrm{~min}, 20 \mathrm{~min}, 30 \mathrm{~min}$ and $60 \mathrm{~min}$, respectively.

\subsection{Acute toxicity study in mice}

(i) Survival, clinical observations, body weights. After the tail vein injection, ten mice injected with melittin in the positive control group died between $10 \mathrm{~s}$ and $4 \mathrm{~h}$. In contrast, the mice in the other groups grew well with thick and glossy fur during the observation period of $15 \mathrm{~d}$. Besides, abnormal phenotypes in behavior, diet, breathing, the hardness and color of their excrements or mental status weren't detected during this period either.

The weights of the mice 5,10 and $15 \mathrm{~d}$ following injection are shown in Figure 6. The weights of the mice in each group increased. Compared with the BSA negative control group and the blank control group, the weights of mice in the exogenous protein group after the different growth periods showed no significant differences $(P>0.05)$ between the male and female mice, which suggested that the exogenous proteins of GL transgenic rice had no significant effect on the weights and other growth indices of mice.

(ii) Serum chemistry. In the male group, The GLB of the exogenous protein group was significantly higher than that of the negative control group and the blank control group $(P<0.05)$. Although $\mathrm{A} / \mathrm{G}$ of the exogenous protein group was higher than that of the blank control group, there was no difference compared to the BSA negative control group. In the female group, the BUN produced by the exogenous protein group was significantly lower than that produced by the blank control group, but there was no difference compared to the BSA negative control group (Table 1). All the serum biochemical indices were within the ranges

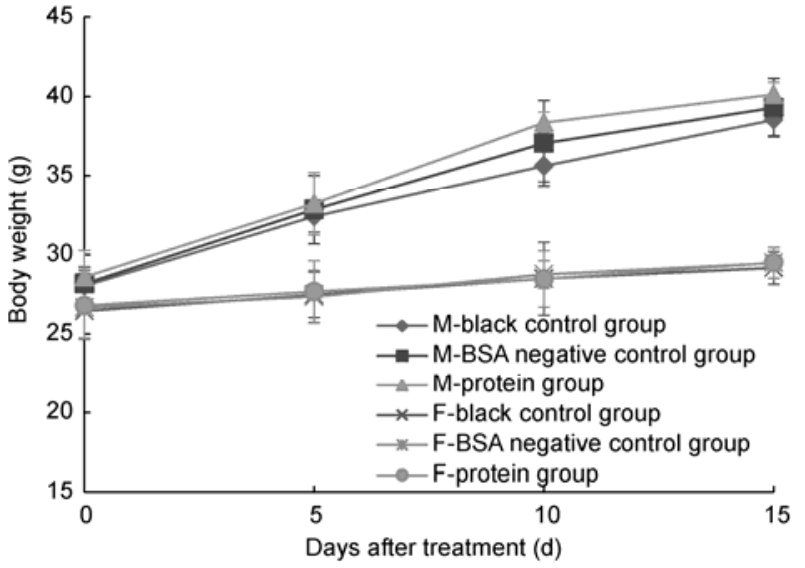

Figure 6 Changes in male and female mice weights in the different experimental groups. The values are presented as mean \pm standard error ( 5 rats/sex/group). M, Male; F, Female.

reported previously [32].

The results above indicated that, compared with the negative control group and the blank control group, the injection of the exogenous protein from the GL transgenic rice showed no harmful effects on the serum biochemical indices of mice.

(iii) Relative organ weight. The changes in relative organ weights following treatment with exogenous protein are summarized in Table 2. In males, there were no statistically significant differences among the groups $(P>0.05)$. In females, although the lung weight of the exogenous protein group was significantly higher than that of the blank control, 
Table 1 Serum chemical data for ICR mice ${ }^{\text {a) }}$

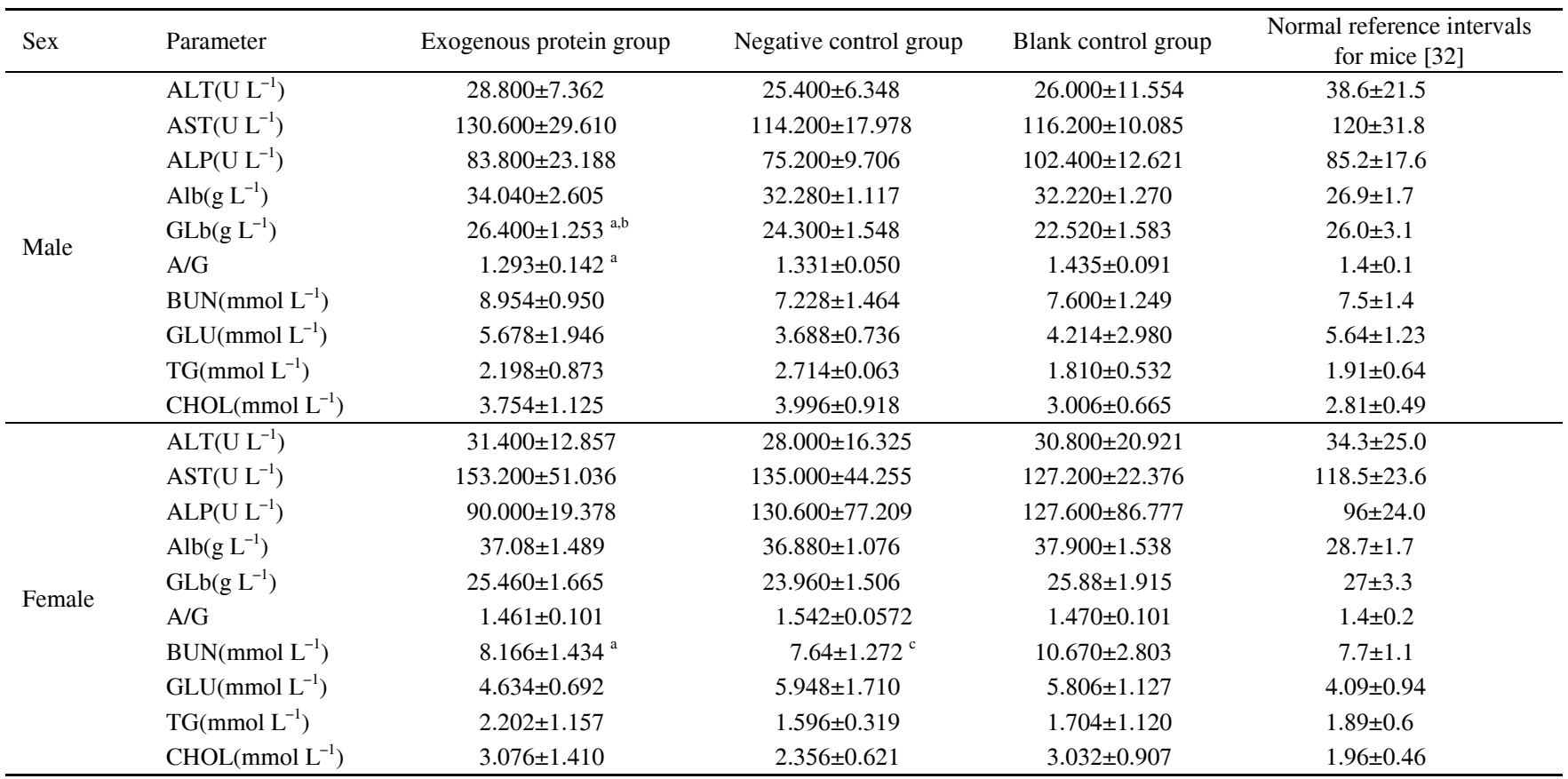

a) a, There was a significant difference between the exogenous protein group and the blank control group $(P<0.05)$; b, there was a significant difference between the exogenous protein group and the negative control group $(P<0.05)$; , there was a significant difference between the negative group and the blank control group $(P<0.05)$.

Table 2 Relative organ weights of ICR mice

\begin{tabular}{|c|c|c|c|c|}
\hline Sex & Organ & Exogenous protein group & Negative control group & Blank control group \\
\hline \multirow{9}{*}{ Male } & Heart & $0.517 \pm 0.072$ & $0.538 \pm 0.088$ & $0.511 \pm 0.060$ \\
\hline & Brain & $1.264 \pm 0.081$ & $1.319 \pm 0.139$ & $1.231 \pm 0.084$ \\
\hline & Thymus & $0.164 \pm 0.031$ & $0.212 \pm 0.052$ & $0.177 \pm 0.060$ \\
\hline & Liver & $4.946 \pm 0.395$ & $4.503 \pm 0.345$ & $4.556 \pm 0.365$ \\
\hline & Lung & $0.554 \pm 0.042$ & $0.635 \pm 0.068$ & $0.548 \pm 0.057$ \\
\hline & Spleen & $0.397 \pm 0.088$ & $0.417 \pm 0.034$ & $0.362 \pm 0.090$ \\
\hline & Duodenum & $0.309 \pm 0.079$ & $0.254 \pm 0.056$ & $0.277 \pm 0.072$ \\
\hline & Kidney & $1.820 \pm 0.246$ & $1.851 \pm 0.312$ & $1.840 \pm 0.324$ \\
\hline & Testis & $0.719 \pm 0.047$ & $0.728 \pm 0.065$ & $0.763 \pm 0.024$ \\
\hline \multirow{9}{*}{ Female } & Heart & $0.581 \pm 0.030$ & $0.539 \pm 0.068$ & $0.516 \pm 0.060$ \\
\hline & Brain & $1.750 \pm 0.139$ & $1.625 \pm 0.198$ & $1.681 \pm 0.135$ \\
\hline & Thymus & $0.283 \pm 0.072$ & $0.276 \pm 0.060$ & $0.232 \pm 0.077$ \\
\hline & Liver & $4.723 \pm 0.257$ & $5.050 \pm 0.295$ & $4.604 \pm 0.812$ \\
\hline & Spleen & $0.424 \pm 0.073$ & $0.400 \pm 0.026$ & $0.349 \pm 0.068$ \\
\hline & Stomach & $0.998 \pm 0.135$ & $0.900 \pm 0.099$ & $0.994 \pm 0.207$ \\
\hline & Duodenum & $0.476 \pm 0.182$ & $0.624 \pm 0.125$ & $0.579 \pm 0.088$ \\
\hline & Kidney & $1.579 \pm 0.049$ & $1.360 \pm 0.280$ & $1.337 \pm 0.121$ \\
\hline & Ovary & $0.121 \pm 0.032$ & $0.116 \pm 0.025$ & $0.098 \pm 0.016$ \\
\hline
\end{tabular}

a) There was a significant difference between the exogenous protein group and the blank control group $(P<0.05)$.

it was not significantly different to that of the BSA negative control group. These results indicated that there were no harmful effects on the organs of mice caused by the injection of exogenous protein.

(iv) Pathological examinations. No abnormalities were found in the brains, hearts, livers, spleens, lungs, kidneys, stomachs, duodenums, thymuses, testes (males) and ovaries (female) of the mice in each experimental group in this study.

The results of the pathological examination are shown in 
Figure 7. No morphological changes were found in the organs of mice in the exogenous protein group, the BSA negative group and the saline control group (Figure 7(a)(1)). There was clear hemolysis in the kidneys and livers of the mice in the melittin positive control group. The liver cells were fuzzy (Figure 7(m)-(o)), and the reason might be that the mice injected with melittin had been affected by stress.

\section{Discussion}

The food safety of GM crops has drawn much attention as the use of GM crops spreads across the world. Considering the importance and influence of rice in food production in China, a more cautious attitude towards the food safety of transgenic rice must be adopted. Transgenic GL gene rice is a new high-lysine GM rice bred by autonomous production in China. Recently, a food safety evaluation of transgenic GL gene rice has been conducted using oral toxicity studies performed in rats [33-35]. For example, the results of Dong et al. [33] demonstrated that feeding transgenic GL gene rice (as $70 \%$ of total feed) to rats for $90 \mathrm{~d}$ did not cause any adverse effects or produce any meaningful histopathological or biological changes. In a similar, but longer-term three-generation study of the effects of transgenic GL gene rice on rats, Zhou et al. [34] reported that the transgenic rice had no adverse effects on the reproductive abilities of rats. The results from these studies suggest that transgenic GL gene rice is unlikely to cause adverse effects and is a non-toxic rice. However, the above studies assessed the safety of transgenic GL gene rice from the whole food/feed perspective and did not study the potential toxicity and allergenicity of exogenous protein, which are focal aspects in the food safety evaluation of GM crops [19,20,36].

Since in vitro digestion models were first used by Astwood [37] in order to evaluate the digestion stability of food allergens, they have become an important part of the safety evaluation of food protein, especially new proteins transferred into traditional foods by biotechnology. In general, if a food protein is allergenic, it has properties that preserve its structure from degradation in the gastrointestinal tract [38]. Therefore, a protein that can be rapidly hydrolyzed by gastric and intestinal fluid is considered less likely to be allergenic $[39,40]$. To date, some exogenous proteins in GM crops (e.g., GFP, Cry, PAT, CP4-EPSPS, PMI, etc.) have been confirmed as digestible in SGF/SIF [17,20,41-43]. In this study, lysine-rich fusion proteins and their degradation fragments were completely digested in SGF within $10 \mathrm{~min}$ and in SIF within 0-15 s, which indicated that exogenous protein was not stable in digestive juice. In addition, this study compared the amino acid sequences of exogenous protein with the sequences of known allergy proteins in the allergen database and no homologies were found [44]. Based on these results, it can be preliminarily concluded that the likelihood of exogenous protein being allergenic is quite small.

As the first step in toxicology studies, acute toxicity testing is used for hazard assessment in mammals after a relatively short time exposure to the test substances and this can provide a reference for the design of the dosage and observational indices needed in further subchronic and chronic testing. In general, acute toxicity testing of transgenic proteins expressed in GM crops is performed in rodents (usually rats) to assess potential toxicity with a single oral exposure to a high concentration of protein or after a number of doses given over $24 \mathrm{~h}$. The animals are then observed continuously for 7-14 d Numerous studies have demonstrated that no introduced proteins tested in GM crops have had a significant acute toxic effect on rodents, even at extremely high doses, such as $2 \mathrm{~m}$ EPSPS $>10 \mathrm{mg} \mathrm{kg}^{-1}$ body weight (intravenous) or $2000 \mathrm{mg} \mathrm{kg}^{-1}$ bodyweight (oral) and PAT > $10 \mathrm{mg} \mathrm{kg}^{-1}$ bodyweight (intravenous) or $5000 \mathrm{mg}$ $\mathrm{kg}^{-1}$ body weight (oral) $[17,28,45]$. In this study, the acute toxicity study in mice was conducted with exogenous protein recovered from the SDS-PAGE gel following intravenous injection. The dose was $438 \mathrm{mg} \mathrm{kg}^{-1}$ body weight,

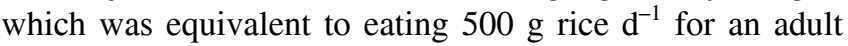
weighing $70 \mathrm{~kg}$. The mice were observed continuously for $15 \mathrm{~d}$ after injection. The results showed that all of the mice in the protein group survived and did not show any adverse effects or clinical signs during the test and the body weights were not significantly different with those of the control groups.

In the serum chemistry tests, ALT, AST, ALP and BUN mainly reflected alterations in liver and kidney function; ALB and GLb mainly reflected the capacity for protein biosynthesis by the liver and TG, CHOL and GLU mainly reflected the blood glucose and lipid metabolism conditions. In this study, no significant differences were found in most of the values of these indicators among the test groups. A few parameters showed differences, but were not biologically significant and all parameter values were within the normal reference intervals for mice of this breed and age [32]. Thus these differences were considered to be unrelated to the exogenous protein treatment. Measurement of the relative organ weights is a simple, direct method used in toxicological experiments in order to assess the effects of xenobiotics on specific organs. These results showed that there were no biologically significant differences between treated and untreated (control) mice. Additionally, no pathological changes in the organs were found following histopathological observation, which indicated that exogenous protein did not produce acute toxic effects in mice.

In conclusion, the results of the in vitro digestion in SGF/ SIF and acute toxicity tests in mice indicated that exogenous protein in transgenic GL gene rice was not associated with any signs of allergenicity or toxicity. 


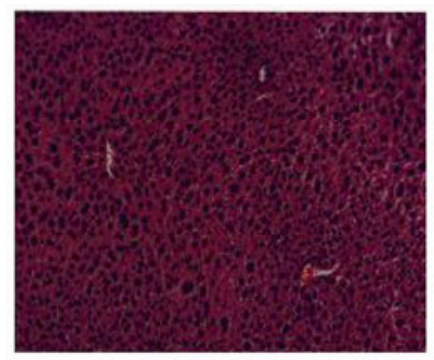

(a) $200 x$

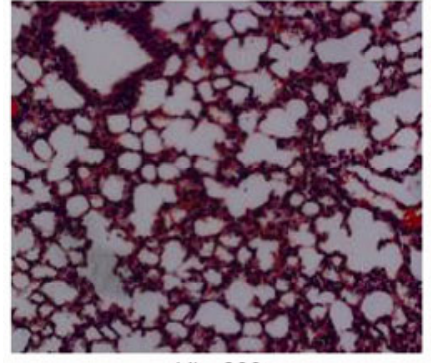

(d) $200 x$

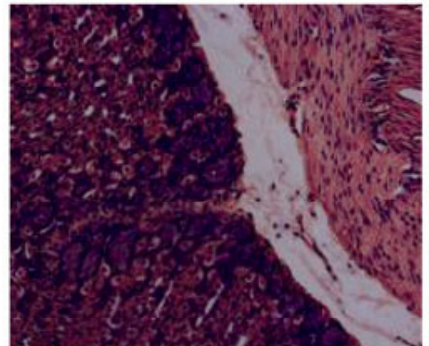

(g) $200 x$

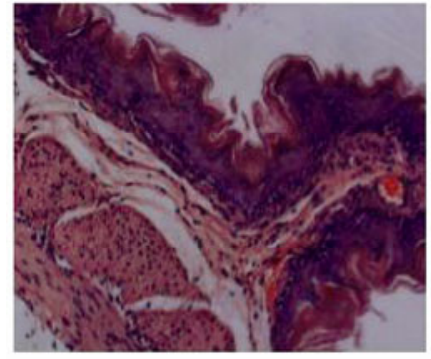

(j) $200 x$

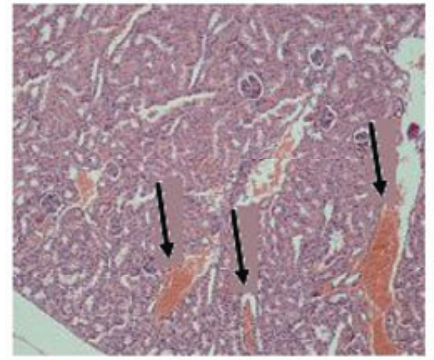

(m) $100 x$

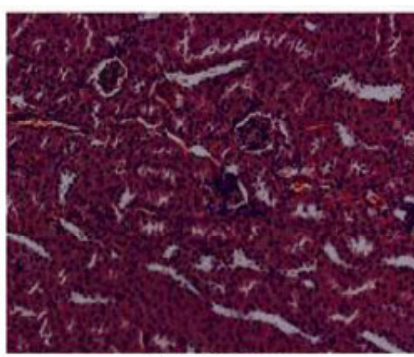

(b) $200 x$

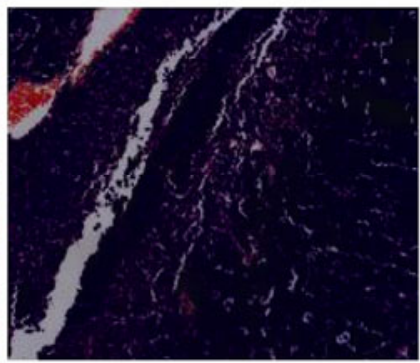

(e) $200 x$

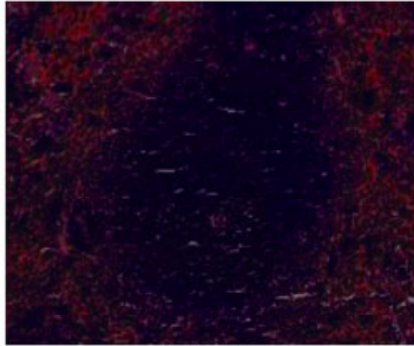

(h) $200 x$

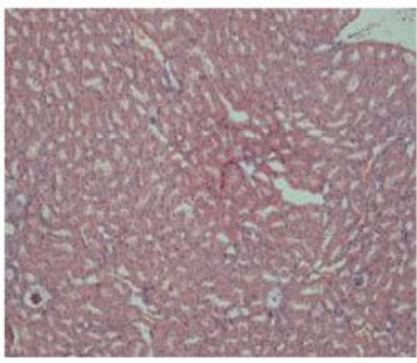

(k) $100 x$

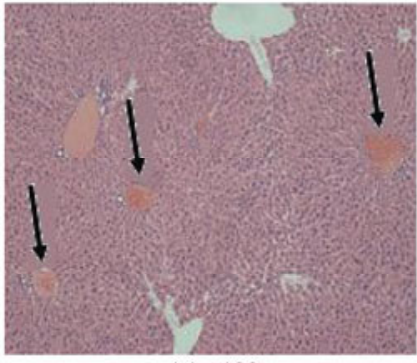

(n) $100 x$

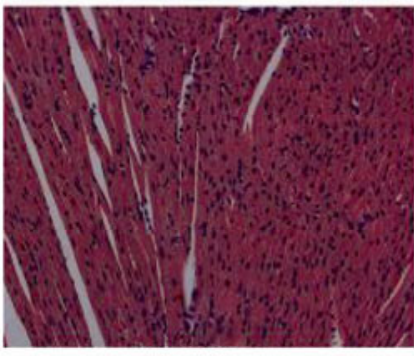

(c) $200 x$

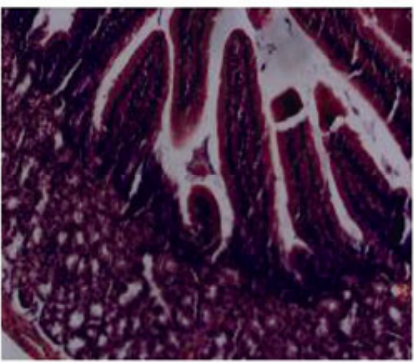

(f) $200 x$

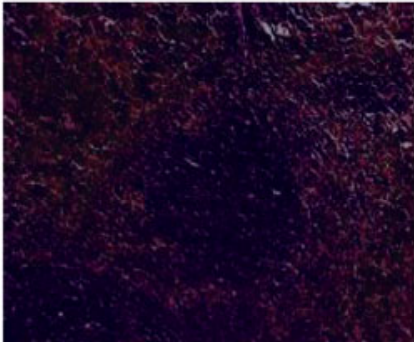

(i) $200 x$

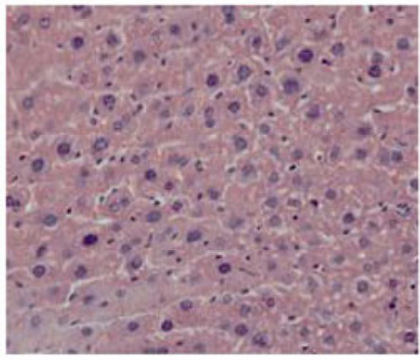

(I) $400 x$

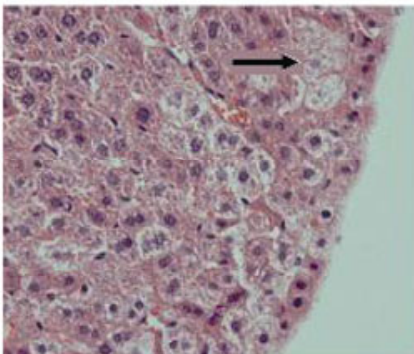

(o) $400 x$

Figure 7 Histopathological examination of the major organs of mice (a-h). No abnormalities were found in the tissue slices from the livers, kidneys, hearts, lungs, pancreases, duodenums, stomachs and spleens of the mice in the exogenous protein group (i-l). No abnormalites were found in the tissue slices from the spleens, stomachs, kidneys and livers in the BSA control group and the blank control group; (m, n) the tissue slices of the kidney and liver of mice in the melittin positive control group. Hemolysis is indicated by the arrow; (o) the tissue slices of the liver of mice in the melittin positive control group. The fuzzy of the liver cell is indicated by the arrow. 
This work was supported by grants from the National Major Special Project for the Development of Transgenic Organisms (2009ZX-08011-003B), Jiangsu Province Qing Lan Project for Young and Middle-aged academic leaders and Jiangsu Province Qing Lan Project for Outstanding Scientific and Technological Innovation Team.

1 FAO. The State of Food and Agriculture 2003-2004. Agricultural biotechnology: Meeting the Needs of the Poor? Food and Agriculture Organization of the United Nations, Rome, Italy. 2004

2 IRRI. IRRI Rice Almanac. Manila, The Philippines. 1993

3 FAO. Rice in human nutrition. Food and Agriculture Organization, Rome. 1993

4 Gao Y F, Jing Y X, Shen S H, et al. Transfer of lysine-rich protein gene into rice and production of fertile transgenic plants. Acta Bot Sin, 2001, 43: 506-511

5 Tang L, Liu Q Q, Deng X X, et al. LRP transgenic indica rice restorer line without resistance selection marker (in Chinese). Acta Agron Sin, 2006, 32: 1248-1251

6 Yu J J, Peng P, Zhang X J, et al. Seed-specific expression of a lysine rich protein $s b 401$ gene significantly increases both lysine and total protein content in maize seeds. Mol Breed, 2004, 14: 1-7

7 Falco S C, Guida T, Locke M, et al. Transgenic canola and soybean seeds with increased lysine. Biotechnology (NY), 1995, 13: 577-582

8 Jones L. Science, medicine, and the future, genetically modified foods. BMJ, 1999, 318: 581-584

9 Delaney B. Strategies to evaluate the safety of bioengineered foods. Int J Toxicol, 2007, 26: 389-399

10 Sorochinskii B V, Burlaka O M, Naumenko V D, et al. Unintended effects of genetic modifications and methods of their analysis in plants. Cytol Genet, 2011, 45: 324-332

11 Halford N G, Shewry P R. Genetically modified crops: Methodology, benefits, regulation and public concerns. Br Med Bull, 2000, 56: 62-73

12 Mosely B E B. Safety assessment and public concern for genetically modified food products: The European view. Toxicol Pathol, 2002, 30: $129-131$

13 Chinese Standard GB15193.1-2003. Procedures for toxicological assessment of food. 2003

14 OECD. Safety evaluation of foods derived by modern biotechnology: Concepts and principles, Organisation for Economic Cooperation and Development, Paris, 1993

15 FAO/WHO. Biotechnology and food safety. Report of a joint FAO/ WHO consultation, FAO food and nutrition Paper 61, Food and Agriculture Organization of the United Nations, Rome, Italy. 1996

16 FAO/WHO. Report of a joint FAO/WHO expert consultation on foods derived from biotechnology. Topic 2: application of substantial equivalence data collection and analyses. Food and Agriculture Organization of the United Nations, Geneva, Switzerland. 2000

17 Hérouet C, Esdaile D J, Mallyon B A, et al. Safety evaluation of the phosphinothricin acetyltransferase proteins encoded by the pat and bar sequences that confer tolerance to glufosinate-ammonium herbicide in transgenic plants. Regul Toxicol Pharmacol, 2005, 41: 134-149

$18 \mathrm{Lu} \mathrm{Y,} \mathrm{Xu} \mathrm{W} \mathrm{T,} \mathrm{Kang} \mathrm{A,} \mathrm{et} \mathrm{al.} \mathrm{Prokaryotic} \mathrm{expression} \mathrm{and} \mathrm{allergenic-}$ ity assessment of hygromycin B phosphotransferase protein derived from genetically modified plants. J Food Sci, 2007, 27: 232-288

19 Delaney B, Zhang J, Carlson G, et al. A gene-shuffled glyphosate acetyltransferase protein from Bacillus licheniformis (GAT4601) shows no evidence of allergenicity or toxicity. Toxicol Sci, 2008, 102: 425-432

20 Delaney B, Astwood J D, Cunny H, et al. Evaluation of protein safety in the context of agricultural biotechnology. Food Chem Toxicol, 2008, 46: S71-97

$21 \mathrm{Xu} \mathrm{W} \mathrm{T,} \mathrm{Cao} \mathrm{S} \mathrm{S,} \mathrm{He} \mathrm{X} \mathrm{Y,} \mathrm{et} \mathrm{al.} \mathrm{Safety} \mathrm{assessment} \mathrm{of} \mathrm{Cry1Ab/Ac}$ fusion protein. Food Chem Toxicol, 2009, 47: 1459-1465

22 Cao S S, He X Y, Xu W T, et al. Safety assessment of Cry1C protein from genetically modified rice according to the national standards of PR China for a new food resource. Regul Toxicol Pharmacol, 2010, 58: 474-481

23 Domingo J L, Giné Bordonaba J. A literature review on the safety assessment of genetically modified plants. Environ Int, 2011, 37: 734-742

24 Liu Q Q. Genetically engineering rice for increased lysine (in Chinese). Doctoral Dissertation. Yangzhou: Yangzhou University, 2002

25 MOA. Ministry of Agriculture of PR China No. 869 Bulletin 2-2007. Food safety detection of genetically modified organisms and derived products. Method of target protein digestive stability in simulative gastric and intestinal fluid (in Chinese), 2007

26 Yamagata H, Sugimoto T, Tanaka K, et al. Biosynthesis of storage proteins in developing rice seeds. Plant Physiol, 1982, 70: 1094-1100

27 Sambrook J, Russell D W. Molecular Cloning. A Laboratory Manual. 3rd ed. New York: Cold Spring Harbor Laboratory Press, 1999

28 Herouet-Guicheney C, Rouquié D, Freyssinet M, et al. Safety evaluation of the double mutant 5-enol pyruvylshikimate-3-phosphate synthase (2mEPSPS) from maize that confers tolerance to glyphosate herbicide in transgenic plants. Regul Toxicol Pharmacol, 2009, 54: 143-153

29 The Chinese Nutrition Society. Dietary guidelines and the Food Guide Pagoda. J Am Diet Assoc, 2000, 100: 886-887

30 Shi Y, Mei S C. Practical Handbook of Medical Animal Experiment. Beijing: China Agriculture Press, 2002. 28-31

31 Schmidt J O. Toxinology of venoms from the honeybee genus apis. Toxicon, 1995, 33: 917-927

$32 \mathrm{Hu} \mathrm{J} \mathrm{W,} \mathrm{Lu} \mathrm{S} \mathrm{M,} \mathrm{Che} \mathrm{L} \mathrm{P,} \mathrm{et} \mathrm{al.} \mathrm{A} \mathrm{probe} \mathrm{into} \mathrm{normal} \mathrm{levels} \mathrm{of} \mathrm{hema-}$ tological and biochemical indexes in 10 kinds of common SPF rats and mice (in Chinese). Lab Anim Sci, 2007, 24: 5-10

33 Dong Y, Shi W D, Zhou X H, et al. A 90-day toxicology study of transgenic rice expressing lysine-rich protein fusion gene in Sprague-Dawley rats (in Chinese). Sci Agric Sin, 2011, 44: 2768-2776

34 Zhou X H, Dong Y, Wang Y, et al. A three generation study with high-lysine transgenic rice in Sprague-Dawley rats. Food Chem Toxicol, 2012, 50: 1902-1910

35 Zhou X H. Toxicological studies on the food safety of two transgenic rice (in Chinese). Doctoral Dissertation. Zhengjiang: Jiangsu University, 2012

36 Chassy B M. Food safety evaluation of crops produced through biotechnology. J Am Coll Nutr, 2002, 21: 166S-173S

37 Astwood J D. Stability of food allergens to digestion in vitro. Nat Biotechnol, 1996, 14: 1269-1273

38 Moreno F J. Gastrointestinal digestion of food allergens: Effect on their allergenicity. Biomed Pharmacother, 2007, 61: 50-60

39 Taylor S L, Hefle S L. Will genetically modified foods be allergenic? Curr Rev Allergy Clin Immunol, 2001, 107: 765-771

40 Taylor S L. Protein allergenicity assessment of foods produced through agricultural biotechnology. Annu Rev Pharmacol Toxicol, 2002, 42: 99-112

41 Momma K, Hashimoto W, Ozawa S, et al. Quality and safety evaluation of genetically engineered rice with soybean glycinin: Analyses of the grain composition and digestibility of glycinin in transgenic rice. Biosci Biotechnol Biochem, 1999, 63: 314-318

42 Privalle L S. Phosphomannose isomerase, a novel plant selection system: Potential allergenicity assessment. Ann NY Acad Sci, 2002. 964: $129-138$

43 Richards H A, Han C T, Hopkins R G, et al. Safety assessment of recombinant green fluorescent protein orally administered to weaned rats. J Nutr, 2003, 133: 1909-1912

$44 \mathrm{Hu}$ X L. Allergenicity and acute toxicity studies of exogenous protein in transgenic rice expressing lysine-rich fusion proteins (in Chinese). Master Dissertation. Yangzhou: Yangzhou University, 2012

45 Merriman T. An acute oral toxicity study in mice with (inert ingredient): Lab project number: DGC-95-A18:3406.2:3406.1. Prepared by DEKALB Genetics Corp and Springborn Laboratories (SLI), 1996. 50

Open Access This article is distributed under the terms of the Creative Commons Attribution License which permits any use, distribution, and reproduction in any medium, provided the original author(s) and source are credited. 